\title{
Post-adjunct Reading Comprehension Questions and Meaning Construction: A Case of Gender Study
}

\author{
Hossein Shokouhi* \\ Shahid Chamran University, Ahvaz, Iran \\ E-mail: shokouhi_hossein@yahoo.com \\ Nabi Parvaresh ${ }^{* *}$ \\ Instructor of TEFL
}

\begin{abstract}
This article explicates on how the post-adjunct reading comprehension questions existing in the Iranian high school and pre-university English textbooks affect the comprehension of the related students. It further purports to see if there is a significant gender difference in the comprehension of reading texts by these student groups. To this end, 240 third-grade high school and pre-university students (equal number of male and female) participated in this investigation. The results demonstrated a significant superiority in the subjects' reading comprehension when they answered the texts with the post-adjunct reading comprehension questions, designed by the researchers for this purpose. The results also showed non-significant gender disparities in the comprehension of given texts.
\end{abstract}

Index Terms—post-adjunct questions, question-specific effect, higher-order questions, meaning construction

\section{INTRODUCTION}

The way reading comprehension is assessed has at least two demonstrable effects on learning from text. First, there is a direct effect that strengthens comprehension specifically related to the quality of information a question asks for. Relatively, a factual question, a question that asks for the plainly stated facts in the text, is different from, for instance, an inferential question which calls for a profound knowledge of the passage. Second, questions may modify mathemagenic activities (assorted activities which give rise to comprehension in a text), and thereby influence the learning of a broad range of information contained in text (Rothkopf, 1970, p. 326). In other words, on the one hand, the utility of the assessing questions that accompany text depends on the question-specific effects and, on the other, on the mental activities that they generally elicit.

In our justification, a majority of post-reading comprehension questions in the Iranian high school and pre-university textbooks are factual ones which ask the learner to repeat or recognize some information exactly as represented in the text. These types of questions may narrow the processing task in reading to solely a rummage around task. In this way, the text is processed only as much as it is necessary to locate information relevant to the questions and processing of all other information ceases as soon as its relevance for the question gets established (Hamaker, 1986, p. 215). This, in turn, might prohibit the mental models to shape and consequently lead to a shallow comprehension of the text (ibid).

Given the aforementioned verity, the current study utilized a composite of post-adjunct reading comprehension questions which were intended to compensate for the above cited possible flaws in the existing reading comprehension questions in the Iranian high school and pre-university textbooks. These questions had two characteristics in common: first, they did not ask only for the superficial information in the text. That is, in order to respond to these questions, the reader is to go beyond the literal meaning of the text and has to engage deeply in the text so that s/he can fully comprehend it. This deep processing can result in a more reflective comprehension of the text (Cha \& Swaffar, 1998, p. 210). Moreover, mental models can be created or shaped through this kind of text processing. These mental models can construct an internal representation of the spatio-temporal relations described in the text (Gordon \& Hanauer, 1995, p. $304)$.

\section{BACKGROUND}

\section{A. Pre-reading and the Activation of Background Knowledge}

\footnotetext{
*Associate Professor of (Applied) Linguistics

${ }^{* *}$ M.A. in TEFL
} 
By providing or activating sufficient prior knowledge, teachers can make the reading task more meaningful, comfortable and also comprehensible for the students. Pre-reading activities can both elicit prior knowledge and give direction to the reader's approach to the passage (Beatie, Martin \& Oberst, 1984, p. 206)

Langer (1984) examined the effect of pre-reading activities on text-specific background knowledge and passage comprehension. Subjects who were randomly assigned to experimental and control groups were 161 sixth-grade students from a middle class suburban school system on Long Island, New York. Treatment sessions consisted of various pre-reading activities. Results suggested that the pre-reading activities significantly raise available background knowledge in treatment groups and this in turn improved their performance on moderately difficult comprehension questions.

Chen studied the effects of previewing and providing background knowledge for American short stories containing uniquely American cultural content on Taiwanese college students' comprehension and attitudes was investigated (1993). A sample of 243 students was randomly assigned to three experimental groups and one control group. The experimental groups received one of three treatments: previewing, providing background knowledge, or both; the control group received no treatment. Each student read two stories and completed pre-tests, short-answer and multiplechoice comprehension post-tests, and an attitude survey. The results on the measures of comprehension were straightforward and made a strong argument for using certain pre-reading activities with Taiwanese college students in the freshman English reading classroom. The post-tests means were in favor of the experimental groups, especially of the previewing and combined groups.

Graphic organizers can be given before the text with the purpose of cognitively activating and clarifying relations among text concepts, thereby fostering deep comprehension. They can be given in different forms or shapes; visual organizers like pictures, maps, diagrams, matrices, etc. and non-visual ones such as vocabulary learning activities, prequestioning techniques and the like.

Kools, Van de Weil, Ruiter, Cruts and Kok (2006) examined the effect of four types of graphic organizers on the comprehension of a health education brochure text and compared subjective with objective comprehension measures. Participants (46 first-year undergraduates from the Department of Psychology at Maastricht University) read a brochure text about asthma with and without these organizers, and subjective and objective text comprehension was measured. It was found that graphic organizers had effects on four levels of objective comprehension as indicated by open comprehension questions. However, on the subjective comprehension measure using Likert-type scales, the groups with and without graphic organizers did not differ from each other.

Aside from graphic organizers, purpose questions placed before reading comprehension passages were meant to provide the information students need to make use of reading strategies they have developed in other types of reading situations. Dunlap (2006) examined the writing and comprehension skills of second grade students using a QuestionAnswer Relationship strategy for pre-reading, during reading, and post- reading, as well as writing, and compared their progress to other second-grade students not using the same strategy. There were 19 elementary students in the experimental group varying in age from 7 to 9 years. They received instruction in a questioning strategy before, while, and after reading (two, forty-minute session). The control group was also composed of 19 elementary students at the same school. The performance of the two groups was compared via a graphic organizer to record topic, main idea, and supporting details when reading an article. Writing samples were scored using the 6 trait analytical rating guide. The results supported the use of questioning skills as a pre-, during, and post-reading effective strategy to increase comprehension of expository text. Subjects using the strategy made significant progress in reading comprehension of expository text and the ability to use the trait of ideas and content in their writing. However, the positive effect of selfquestioning on the use of organizing their writing was not supported.

Among other different pre-reading activities, pre-teaching vocabulary seems to be the only activity which is broadly overemphasized in textbooks including Iranian high school English ones. This activity in books under study is directly practiced in a section called 'New Words' at the beginning of each lesson. Some new words are presented through typical sentences in this section.

\section{B. While-reading Activities}

Among the while-reading activities, reading aloud and silent reading are two major types. There seem to be two contrasting views concerning reading aloud. One sees reading aloud beneficial (Salasoo, 1986, p. 59) and motivational (Ecroyd, 1991, p. 71) for reading comprehension and the other sees oral reading not a very authentic reading activity and with significant disadvantages (Brown, 2001, p. 312).

In one study, Gatsakos (2004) wished to see if reading aloud to foreign language children on a regular basis had a positive effect on their reading comprehension. The subjects $(\mathrm{N}=75)$ were second graders at a Crystal Lake, Illinois, school. The children were randomly selected, classified and assigned to one of three groups of academic performance: low, average, and high ability. Eight reading lessons were taught to them. Four were lessons involving two exposures to silent reading. The other four involved one silent reading time and one reading aloud time by the teacher. The hypothesis was that those children who were read aloud to would have higher levels of comprehension, based on four comprehension questions administered after each story, as compared to those children who read silently.

There were statistically no significant differences in comprehension when students were read aloud to or when they read silently. However, students of higher ability indicated higher level of comprehension than did students of lower 
ability, regardless of whether they were read to or read silently. Comprehension was measured as being comprised of sub-scores representing literal, inferential, critical, and strategic questioning. No significant differences between student sub-scores for literal, critical, or strategic questions were found either. Students in silent-reading conditions scored significantly higher on inferential questions. Students with higher levels of ability scored significantly higher on all subscores.

The conventional wisdom in some studies of this kind is that silent reading encourages an emphasis on meaning rather than on surface-level features of text and hence facilitates a deeper, more elaborate processing of text. Brown (2001, p. 312) subcategorizes silent reading performance into intensive (direct) and extensive (indirect) reading. Intensive reading which is more class-oriented calls the students' attention to grammatical forms, discourse markers, and other textual details for the purpose of understanding literal meaning, implications, rhetorical relationships, and the like. Reading for pleasure and usually out of classroom is done more extensively. In contrast to intensive reading, extensive reading is more relaxed and less concentrated. One of the main benefits of extensive reading is providing an increased word recognition (Harmer, 2001:200)

\section{Post-reading Activities}

The assessment of the students' comprehension of the texts is mainly done in this stage. Teachers can evaluate the students' comprehension in variety of techniques (top-down, bottom-up or interactive) and activities. Nuttall (1996, p. 212) emphasizes the similarities between testing and teaching in this sense. She believes that the design of exercises or classroom activities does not in principle differ from the design of test items. So these techniques, with both teaching and testing values, can focus on the student's ability for implication, draw conclusion (inference), summarize, give opinions, debate and discuss, identify key ideas, point out organizational details, describe the author's intentions, compare, etc. Chastain (1988, p. 228) believes that the criterion for an effective post-reading activity is that it requires students to reprocess the material from reading. One key factor concerning the type of questions is that we must know these assessing questions are not tests of memory, but a way to direct students' attention to the text ( though not the only way).

\section{Inferencing}

Winne, Graham and Prock (1993) pinpointed the effects of explanatory feedback on the poor readers' text-based inferencing. Twenty four third-to-fifth grade poor readers read passages that included five types of information: problem statement, rule related to the problem, critical fact fitting the rule that solved the problem, spurious information that apparently would solve the problem and facts. In instruction, an inference question followed by one question about each type of information was asked. In an inductive condition, tutors provided specific feedback about students' answers to all six questions and students had to induce processes. In an explicit condition, tutors added to feedback by explaining and demonstrating the process for combining information about the problem, rule and critical fact to create an inference. Both instructional conditions boosted overall comprehension, but inference-making was detectably better when students received explicit feedback.

\section{Summarizing or obtaining the gist}

Written or oral summary after reading the text can be used as a fostering or assessing way of comprehension. The task of summarizing a text can be demanding for high school students if it is not accompanied by a sufficient command of writing and speaking ability.

Oded and Walters (2001) scrutinized the extent to which tasks involving processing differences in English as a foreign language (EFL) reading result in differences on comprehension. Processing differences were created by the assignment of two different tasks-writing: a summary of a text and listing the examples in a text. Text comprehension was measured by performance on a set of comprehension questions. The qualitative processing required in selecting main ideas and organizing theme in a summary was expected to lead to greater comprehension. The task of listing details, being an irrelevant or distracting task for overall comprehension, was expected to result in poor comprehension.

Sixty five undergraduate students at an Israeli university participated in this study. They were drawn from four classes, three of them $(\mathrm{N}=43)$ at 'the low-advanced' level who underwent 108 hours of instruction and the other one $(\mathrm{N}=24)$ at 'the high-advanced level' with 54 hours of instruction. The results of the study showed that for the lowadvanced group there was no significant difference in comprehension performance of the contents of the two texts under study (one titled Animal and the other Nature) in the 'example' condition (in which the participants had to list the examples provided by the writer), while for the 'summary' condition, a significant difference for the comprehension performance of the contents of both of these texts was observed. On the whole, the subjects who did the summary task performed better on the comprehension task (Oded and Walters, 2001, p. 363). The researchers concluded that the extra processing required in the writing of a summary of the main points would help produce a better encoding of the text. Working hard to produce a summary, then, as they claim, increases comprehension of a text.

\section{Discussion and debate}

By discussing the content of the text after or before reading it, students can be given the opportunity to engage in the reading text: question it, explain it, and relate it to their own real lives, as they are more likely to comprehend it. Silberstein (1994, pp. 44, 61) sees discussion as both a pre-reading activity in which we build interest and background for the text and as a post-reading activity to evaluate the ideas presented in the text. 
Discussing or debating the text is very advantageous as a social activity in Fairbairn and Fairbairn's view (2001, p. 165). They believe that discussing the text in group means not only you do not have to take the sole responsibility for understanding but it gives you the opportunity to share a number of different viewpoints or different 'takes' on the same information, the chance to clear up misunderstanding and uncertainties, and it can help you develop a better understanding of what the author is arguing or reporting.

Snyders (2005) evaluated the effects of student-centered collaborative discussion of social studies texts on middle school students' comprehension, writing quality, and motivation. He explored what would happen if the instruction was changed so that middle school students had the opportunity to: a) read informational texts related to their social studies topic, b) discuss the content in small groups and c) follow the discussions and respond to those texts in writing. The study involved two classrooms of general level seventh-grade students in an English class at a small Midwestern middle school (examining the Holocaust) in a pre- and post-test design. The results of the study indicated that students who had the opportunity to talk about the readings in small peer groups used significantly higher levels of thinking and exhibited more literate register cohesion in their written responses.

\section{METHOD}

\section{A. Subjects}

A number of 240 high school students (third-graders and pre-university) with 120 high school and 120 pre-university took part in this investigation. They were selected randomly from among all high schools and pre-university centers in Gachsaran, a southern city in Iran. The subjects were equal number of males and females. They were in the age range of seventeen to nineteen.

\section{B. Instruments}

Since Iranian English textbooks for grades 1, 2, and 3 of high school use approximately the same procedure in the presentation of the post-reading comprehension questions, English book three of high school as a representative for high school textbooks and pre-university textbook were selected to this end. Expository texts were used because the participants were more familiar with this genre in their educational setting and textbooks. The passages selected for the main part of the study had to be compatible with those of the high school and pre-university textbooks in terms of text difficulty. For this objective, using Fog index of readability (Farhady, Jafarpoor and Birjandi, 1996, p. 282), the average text difficulty of the English book three of high school and the pre-university textbook was calculated. It was tallied to be 17.05 for the English book three and 19.38 for the pre-university textbook, respectively.

There were five other passages each with six questions, a total of 30 -item test. The six questions were the postadjunct comprehension questions based on the most common post-reading assessment activities provided in their high school and pre-university textbooks (e.g. free response, multiple choice and true-false items). Apart from this, two other tests of reading comprehension with the same contents and item numbers were constructed on the basis of different forms of post-reading questions, such as test of main ideas, test of implicit ideas, drawing inferences, cloze procedure. Finally, two other tests, one for high school and one for pre-university students, each containing three authentic reading comprehension passages were given to the subjects. These texts taken from the NESWEEK and TIME magazines had nearly the same average readability to the previous tests. Each was followed by 10 post-reading comprehension questions similar to those in the second tests mentioned above. They were given to the subjects after the second tests with non-authentic passages. After calculating the results of the previous tests, to obviate the possible ambiguities, each grade took another test containing authentic passages similar to the previous authentic ones. These tests were administered after about one month of running the first tests of authentic passages.

\section{Procedure}

Two reading comprehension tests each containing five gender-unbiased passages with approximately the same level of difficulty to the high school textbooks were given to the high school students. The first test contained five reading comprehension passages followed by 30 post-adjunct questions, six questions for each passage. These were closely similar to the ones presented in their textbooks (e.g. free response, multiple choice and true-false items), and with an average text difficulty of $17.03^{1}$. The second test also incorporated five passages, with an average text difficulty of $17.11^{2}$, followed by 30 post-adjunct reading comprehension questions other than their textbooks. This test contained items on main ideas, implicit and explicit ideas, drawing inferences, summary cloze, and summarizing items. These two tests were administered and compared through paired t-tests. The purpose of this analysis was to compare the effects of these two different kinds of post-adjunct reading comprehension assessment on the subjects' reading comprehension.

The same procedure was repeated for the pre-university students. The only difference was that the texts in the first test designed for pre-university students had the average readability of $19.34^{3}$, while the texts in the second test had the average readability of $19.42^{4}$.

\footnotetext{
${ }^{1}$ The average difficulty of first texts for high school using Fog index of readability

${ }^{2}$ The average difficulty of second texts for high school using Fog index of readability

${ }^{3}$ The average difficulty of first texts for pre-university using Fog index of readability
} 
As formerly mentioned, all the texts were expository. The topics of all reading passages were general and not technical (e.g., humanities, general knowledge, social sciences, and natural sciences directed at general readers). To be more compatible with high school and pre-university English textbooks, the selected reading passages were between 250 and 450 words in length.

In order to achieve more reliability, the right/wrong scoring procedure was used in this study. Therefore, a response received a score of ' 0 ' if it was wrong and ' 1 ' if it was correct. There was no penalty for the incorrect answers.

For subjectively scored items, open ended items such as completion items, writing summary items, etc., four raters participated in scoring (the researchers and two other English teachers). General impression marking was used to score such items because of its ease and its time-saving nature. Moreover, partial credit scoring (Bachman \& Palmer, 1996, p. 202) in which responses can be scored on several levels ranging from no credit ' 0 ' to full credit ' 1 ' with several levels in between $\left(0, \frac{1}{2}, \frac{1}{4}, \frac{3}{4}\right.$, and 1$)$ was used.

\section{Data Analysis}

To determine whether the difference of the participants' performance on reading comprehension was significant in each test, we applied the paired t-test technique of comparing means where means of the subjects are compared with each other. Test of one-way ANOVA was used to determine the effects of gender and various post-reading comprehension questions on the subjects' overall comprehension of the given texts at each stage.

\section{E. Research Questions and the Hypotheses}

To achieve the purpose of the study, the following three questions were formulated:

1 How do the post-reading comprehension activities in high school and pre-university English textbooks affect the comprehension of the related students?

2 Is there a significant gender difference in the comprehension of reading texts in high school and pre-university textbooks among Iranian EFL related students?

3 Do authentic reading texts affect the subjects' reading comprehension?

To respond to the above-mentioned questions, three null hypotheses were formulated accordingly.

\section{RESUlts}

What follows is a presentation of the results obtained from the analysis of the subjects' performances on the above mentioned tests.

TABLE 1.

MATCHED T-TEST OF THE STUDENTS' PERFORMANCES IN THE TWO TESTS

\begin{tabular}{|c|c|c|c|c|}
\hline Subjects & Test No. & $\mathrm{n}^{\text {Mea }}$ & SD & $\mathrm{t}_{O}$ \\
\hline \multirow[t]{2}{*}{ High school males } & 1 & $6^{16.9}$ & 6.43 & \multirow[t]{2}{*}{$25^{2.7}$} \\
\hline & 2 & 518.1 & 5.21 & \\
\hline \multirow[t]{2}{*}{ High school females } & 1 & $2^{18.3}$ & 6.04 & \multirow[t]{2}{*}{$70^{3.5}$} \\
\hline & 2 & $\begin{array}{ll} & 19.4 \\
0 & \end{array}$ & 5.54 & \\
\hline \multirow[t]{2}{*}{ Pre-university males } & 1 & $\begin{array}{ll} & 16.8 \\
7 & \end{array}$ & 6.57 & \multirow[t]{2}{*}{$05^{2.1}$} \\
\hline & 2 & $\begin{array}{ll} & 17.7 \\
7 & \end{array}$ & 5.37 & \\
\hline \multirow[t]{2}{*}{ Pre-university females } & 1 & $5^{18.4}$ & 6.55 & \multirow[t]{2}{*}{$09^{2.3}$} \\
\hline & 2 & 119.0 & 5.93 & \\
\hline
\end{tabular}

For high school males, the result was $t=2.725>2.021$. The $t$-observed value exceeded the value of the $t$-critical at 0.05 level which meant the existence of a significant difference between the subjects' means in the two tests. For high school

\footnotetext{
${ }^{4}$ The average difficulty of second texts for pre-university using Fog index of readability
} 
females, the result was $t=3.570>2.021$. The $t$-observed value from this analysis also exceeded the $t$-critical value and this meant the subjects' means were significantly different in the two tests.

To shed more light on the differences between the means of the pre-university students in the two tests, paired t-tests were run again. For males, the result was $t=2.105>2.021$. The $t$-observed value exceeded the value of the $t$-critical at 0.05 level which indicated a significant difference between the subjects' means in the two tests. For females, the result was $t=2.309>2.021$. The $t$-observed value form this analysis also exceeded the $t$-critical at the 0.05 level and this indicated the subjects' means significance in the two tests. Considering post-reading activities as the independent variable, tests of one-way ANOVA were conducted in order to pinpoint whether gender differences (moderator variable) affected students' performances in reading comprehension (dependent variable) in the two tests. Table 2 portrays the results of one-way ANOVA for the subjects.

TABLE 2.

ONE-WAY ANOVA FOR GENDER DIFFERENCES IN THE TWO TESTS

\begin{tabular}{|c|c|c|c|c|c|}
\hline Subjects \& Test No & Source & SS & $\overline{d f}$ & MS & $\mathrm{F}$ \\
\hline \multirow{2}{*}{ High school/ 1} & Between group & 1208.163 & 1 & 44.747 & \multirow{2}{*}{1.15} \\
\hline & Within group & 1238.771 & 118 & 38.712 & \\
\hline \multirow{2}{*}{ High school/ 2} & Between group & 692.446 & 1 & 25.646 & \multirow{2}{*}{0.89} \\
\hline & Within group & 914.704 & 118 & 28.585 & \\
\hline \multirow{2}{*}{ Pre-university/1 } & Between group & 1784.400 & 1 & 54.073 & \multirow{2}{*}{$2^{1.84}$} \\
\hline & Within group & 763.413 & 118 & 29.362 & \\
\hline \multirow{2}{*}{ Pre-university/ 2} & Between group & 968.846 & 1 & 33.408 & \multirow{2}{*}{$2^{1.36}$} \\
\hline & Within group & 735.867 & 118 & 24.529 & \\
\hline
\end{tabular}

For high school students, as Table 2 shows, the F-observed value, 1.156 at 1 and 118 degrees of freedom is lower than the critical F-value, 3.94 for the first test. Result of the second indicates that the F-observed value, 0.897 at 1 and 118 degrees of freedom was much lower than the critical F-value, 3.94. These results indicate that the effect of gender was very low and not statistically significant in the two tests. However, there was a trend toward meaningful differences which could be attributed to gender in the first test, but the F-ratio is too small to make us confident.

For pre-university students, the result of one-way ANOVA in the first test reveals that the F-observed value, 1.842, in 1 and 118 degrees of freedom was lower than the F-critical value, 3.94. In the second test, F-observed value, 1.362 in 1 and 118 degrees of freedom was also lower than F-critical value. Although there was a trend toward meaningful differences which could be attributed to gender in these tests, the F-ratio was not appreciable in this sense. These results also indicate that the effect of gender was low and not statistically significant in the two tests.

\section{DISCUSSION}

\section{A. Cognitive Level of Adjunct Questions}

According to the results obtained from the paired t-tests for both high school and pre-university subjects in Table 1, the corresponding null hypothesis to the first research question as to the effect of various reading comprehension questions, as post-reading activities, on the subjects' comprehension of the given texts is rejected. The results suggest that different test formats yield different levels of comprehension and they seem to measure different aspects of reading comprehension.

Theorizing about adjunct questions has two tasks (Hamaker, 1986, p. 237). One is to explain how adjunct questions are effective and the other is to predict under what condition they are effective or ineffective.

Concerning the howness of the effectiveness of such questions, the results of this experiment can support the notion that higher-order adjunct questions, "questions which ask the students to mentally manipulate bits of information previously learned to create an answer, or to support an answer with logically reasoned evidence" (Winne, 1979 cited in Hamaker, 1986, p. 213), are more likely than factual ones to produce facilitation for the comprehension of the texts. This approach acknowledges that information may be processed at surface levels or at deeper semantic levels, with deeper processing associated with better retention of meaning. This assumption is corroborated by a number of supplemental supports. First, the underlying supposition is that the depth of processing required in the task of answering higher-order adjunct questions, e.g. inference questions, finding main idea questions, implication questions, paraphrase questions, etc., would ensure quality encoding of the content, and hence better comprehension of the text. The 
assumption common to all higher order adjunct questions is that this type of question induces in the learner higher order processing activities, such as integrating and elaborating (Ellis, Wulfeck \& Montague, 1980, p. 452; Hamaker, 1986, p. $238 \&$ Thompson, 1987, p. 96). This, in turn, causes an extra processing on the part of the reader and, thereby, fosters comprehension.

This line of thinking also coincides with Andre's model of productive learning (1979), asserting that pedagogical devices, such as post-adjunct reading comprehension questions, influence learning by changing the learner's perception of his tasks and the strategies chosen to accomplish the tasks. The effect of adjunct questions is conditioned on the basis of the learner's information processing system. This model implies that the effect of high-level adjunct questions is specific to the ideas presented in them.

Second, the use of higher-order adjunct questions adjoins a new facet to the discussion: the level of the effect. Most higher-order adjunct questions concern higher-order effect; i.e., the influence of adjunct questions on the learners' ability to use the text information in a variety of higher order tests, such as inference and application questions which, as previously mentioned, can induce in the reader higher order processing. In addition, these types of questions are often seen to affect the retention of the text information. This is referred to as lower-order effect of higher-order adjunct questions (Hamaker, 1986, p. 215). Both effects are referred to as "mathemagenic activities" (Rothkopf, 1970, pp. 325 $\& 327$ ), which means activities that give rise to learning. It is highly likely that the subjects' better performance in the second test would be due to the clear-cut advantages taken from the availability of such effects.

Third, the result of this experiment also provides insight into the nature of the backward process that occurs when the subjects encounter a combination of explicit and implicit high-level adjunct post-questions in conjunction with the expository texts. This conscious processing introduces not only coherence to information contained in the text, but also a productive comprehension strategy (Cha \& Swaffar, 1998, p. 210). Further, rereading is encouraged in such a model and this technique notably enhances text comprehension (Rickards, 1979, p. 188). A behaviorist interpretation of adjunct question views this effect as one of reinforcing the reader through stimuli (the questions) and thus shaping the reader's mental processing of the text. This shaping power can be more verified if we reflect on the conception that higher-order adjunct questions solicit information similar, but not identical, to the ones in the texts. In this regard, the second test in the current experiment contained items, i.e. inferential and summary questions, which had the potential to make the subjects engage in a conscious processing achieved by dwelling upon the questions and re-reading the texts.

Fourth, the results also substantiate the 'Arousal Hypothesis' traditionally discussed by Natkin and Stahler (1969) and Bull (1973). According to this hypothesis, adjunct questions can serve as motivating and demotivating devices. A question with high arousal potential would be one which maximizes incompatible response tendencies, i.e., causing conceptual conflict (Bull, 1973, p. 85). For instance, the question "What do ants grow in their underground farms?" causes conceptual conflict in that it seems to contain incompatible ideas such as ants as farmers and underground farms. However, to resemble the questions in the Iranian high school textbooks, some of the MC questions used in the first test of the present study were comparably factual or as Kohn (1994, p. 27) believes, "right there questions", the questions whose answers are written clearly in the text. Usually, in such questions, both the question and the sentence including the answer use the same words. For example, in the question "The average child will watch ----- murders on TV before finishing elementary school." among the four alternatives a) 2000 b) 8000 c) 3000 d) 4000 ; the correct answer, choice b, is found very effortlessly by the reader since it apparently exists in the text. Therefore, there would be no incompatible response tendency on the part of the question and it no longer causes conceptual conflict inside the reader.

These types of questions whose answers were restricted to particular sets in the texts may have had low arousal potential because they aroused little subjective uncertainty or conflict. They might not have caused conceptual conflicts since they required little reduction of information. This can be discussed in light of the interaction effect between the degree of arousal and amount of retention. When the arousal level is high, the retention is also high and when it is low, the retention is low too (Natkin \& Stahler, 1969, p. 431). Conceptual questions in the second tests might have aroused the subjects' interest and motivation and thereby fostered comprehension.

Finally, in addition to question-specific facilitative effects, the multiple strategic measures applied in the second tests of the present study can account for the superiority in the subjects' reading comprehension. This can be vindicated in two interrelated justifications: 1) attention to macrostructure of a text would lay the foundation for a mental model which would enable further mapping of the text (Gernsbacher, 1990, p. 135 \& Oded and Walters, 2001, p. 363); 2) conversely, the low-level processing required in answering the factual questions is expected in more superficial encoding, with more attention to solely microstructures. Respectively, the results of the present study partly support Oded and Walters' (2001, p. 365) contention that summary task and finding main ideas (two activities assigned to tap the text macrostructure) as post-reading tasks in a text would result in a deeper comprehension of the text. As the postadjunct comprehension questions designed by the researchers were more conceptual and comprehensive in nature, focusing on both micro- and macro-structures, the subjects might have gained a priori comprehension by concentrating on important information and forming a mental model of the text. This lends support to Brown's (2004, p. 188) argument that the assessment of reading comprehension can entail the assessment of a storehouse of reading strategies. Moreover, it gives conspicuous support to the Cha and Swaffar's (1998) procedural model as an approximation of 
reader processing. From the standpoint of cognitive activity, this model is a précis format assuming that reading comprehension is multi-faceted which principally occurs at macro- and micro-levels.

\section{B. Test Taking and Meaning Construction}

The results of this study can support the hypothesis that a reader's mental model continues to develop throughout the test taking process (Gordon \& Hanauer, 1995, p. 299). Taking this one step further, it can be assumed that if information from test question is incorporated in a reader's mental model, the meaning constructed by a reader of the stimulus text continues to revise and/or to expand as a result of interacting with comprehension questions. Accordingly, besides knowledge of the text, knowledge of the world, and linguistic knowledge, the testing task itself can be considered as an additional knowledge source which develops the test taker's mental model (ibid).

In this sense, how much thinking students engage in while they process a text deserves scrutiny because the extent and depth of it apparently affect their subsequent strategy use critically. The application of various reasoning strategies appears to be influenced by the specific type of question. This can result in a situation where particular reasoning strategies are associated with specific question types such as questions of inference and main idea (Kavale \& Schreiner, 1979, p. 121). The comprehension demand of the questions can be discussed in light of the psychological notion of 'mindfulness'. The reasoning strategy of mindfulness is defined as the "volitional, metacognitively guided employment of non-automatic, usually effort demanding processes" (Wong, 1994, p. 111). If learners are challenged by tasks that are novel, moderately challenging or ambiguous, mindfulness will be resulted. Any task condition that promotes mindfulness will enhance performance. That is, when a student is mindfully engaged in a learning task, performance is enhanced, attention is more sharply focused, and motivation is greater. The inferential and main idea questions in the second tests of the present study might have brought about mindful engagement of the subjects and fostered their comprehension $(\mathrm{t}=2.725>2.021$ for high school males, $\mathrm{t}=3.570>2.021$ for high school females, $\mathrm{t}=2.105>2.021$ for preuniversity males, and $t=2.309>2.021$ for pre-university females (see Table 1 above).

\section{Gender effect}

On the basis of the results of one-way ANOVAs in Tables 2 and 3, the answer to the second research question is that there are no significant gender differences in the comprehension of both non-authentic and authentic reading texts. Accordingly, the corresponding null hypothesis to the second question regarding no gender differences between the subjects (high school and pre-university) in reading comprehension of all the given texts is verified.

TABLE 3

ONE-WAY ANOVA FOR GENDER DIFFERENCES BETWEEN STUDENTS IN THE FIRST TEST WITH AUTHENTIC PASSAGES

\begin{tabular}{|c|c|c|c|c|c|}
\hline Subjects & Source & SS & df & MS & $\mathrm{F}$ \\
\hline \multirow{2}{*}{ High school } & Between group & 812.025 & 1 & 28.001 & \multirow[t]{2}{*}{$6^{1.05}$} \\
\hline & Within group & 795.125 & $18^{1}$ & 26.504 & \\
\hline \multirow[t]{2}{*}{ Pre-university } & Between group & 642.350 & 1 & 23.791 & \multirow[t]{2}{*}{$\begin{array}{l}0.75 \\
4\end{array}$} \\
\hline & Within group & 1009.896 & $18^{1}$ & 31.559 & \\
\hline
\end{tabular}

At the outset, it must be reminded that any study on gender-related differences must acknowledge that the effect of the sex variable is dependent on the task performed and the circumstances under which the task is carried out (Nyikos, 1990, p. 273). Therefore, the findings of gender studies in the field of reading comprehension can vary depending on multiplicity of factors (Phakiti, 2003, p. 652).

A predominate feature in most of gender related studies is the effect of text type or text characteristics. Genderrelated characteristics of the texts have been confirmed to account for the superiority or inferiority of one sex to the other in some of these studies (e.g. Scott, 1986; Bügel \& Buunk, 1996; Brantmeier, 2003; Phakiti, 2003 \& Pae, 2004). The contribution of text type and topic to such gender-related studies can be viewed psychologically and culturally. Psychological reader-response theories and cultural approaches to textual interpretation (Griswold, 1987, p. 1105) alike assume that reading experience is shaped to some degree by patterns of identification or similarity between the reader and the characters or experiences in the text. This leading effect of text characteristics can support the conclusion that gender-biased text may lead in gender differences and conversely gender-unbiased texts may result in no gender differences in comprehension. With this in mind, a possible explanation for the lack of gender differences in the present study in overall reading comprehension scores is that all the texts were sex-fair or gender-unbiased.

Gender-related preferences in text topic have been also shown to have a determining factor in some gender related studies (e.g. Bügel \& Buunk, 1996; Brantmeier, 2004). In these studies, patterns of preference (text topic preferences) are reflected in the readers' performance on the tests of reading comprehension. The assumption that there is better memory for stimuli that is consistent with societal stereotypes about males and females (Bigler \& Liben, 1990, p. 1441) can be exploited in order to lend credibility to this fact. As stated formerly, sex-fair text topics, topics which are not 
bound up with a particular sex, were utilized in the present study. Thus, the incongruity of text topics to the genderstereotyped patterns could counteract or diminish the sex-oriented effects.

Text genre and the difficulty level of the text are shown to be other features for the disparities in the findings of some gender-related studies (e.g. Bacon, 1992; Bügel \& Buunk, 1996; Brantmeier, 2003). In Bügel and Buunk (1996) males reported that they read articles and magazines about specialized topics. For example, the greater experience with linguistically complex texts was discussed to lead in males' superiority in reading comprehension in the above study. However, in the present study, all the texts were controlled in difficulty level and non-technicality in nature.

Yet another factor for the sex-based differences in such studies can be the proficiency level of reading comprehension in English (e.g. Scott, 1986; Bügel \& Buunk, 1996; Brantmeier, 2003). Male and female students differ in background: they have different interest, reading habits, and aspirations. However, there is no generally agreed upon way to assess such knowledge. This is in part due to the fact that prior knowledge and schemata are rather global concepts, and this is very difficult to show (Bügel \& Buunk, 1996, p. 17). In the current study, authentic and nonauthentic texts written for public were used for assessment. Prior knowledge was very difficult to be measured in such texts because they were not about specialized subjects and they did not have specific vocabulary (ibid). Therefore, these features possibly neutralized the effect of a specific gender background on the obtained results. Furthermore, the subjects in the present study might have been different from the other gender related studies. For example, they were all from the same age, had relatively similar range of English proficiency levels, and showed approximately the same cultural and educational context. As a result, the homogeneity in the subjects' background may account for the similarities in their performance.

This issue can also be elucidated in the light of 'gender schema theory' and the way 'sex-stereotyping' is used. What gender schema theory proposes is that the phenomenon of sex type derives, in part, from gender-schematic processing or sex-stereotype (Bem, 1983, p. 607). It can also derive from constellation of traits and roles generally attributed to men and women. This sex-stereotyped schema may become more flexible when there will be more overlap between male and female things (Martin \& Halverson, 1981, p. 1130). Using gender-unbiased texts, as a possible means to provide the overlap, might have attenuated the aspects of stereotyping and relatively caused the sex-role to become less evaluated and less central in the thinking of the subjects in the present study. Accordingly, the results can somehow endorse the non-significant effect of non-sex-typed texts to be less discriminating.

To sum up, for a gender study to be sex discriminating, it should acknowledge some general features. For instance, it should use gender-biased text topics and contents. The text genre and the difficulty level of the text should be specialized to one sex proficiency and background. Intentionally or unintentionally, if these interfering factors are not applied to the methodology of any gender-related study concerning reading comprehension, the results of the comparison might become indiscriminatory and both sexes possibly perform similarly. The results of the present study indicate a non-significant difference between males and females' reading comprehension $\left(\mathrm{F}_{O} 1.156<\mathrm{F}_{C} 3.94\right.$ for high school students in the first test, $\mathrm{F}_{O} 0.897<\mathrm{F}_{C} 3.94$ in the second test, $\mathrm{F}_{O} 1.842<\mathrm{F}_{C} 3.94$ for pre-university students in the first test, and $\mathrm{F}_{O} 1.362<\mathrm{F}_{C} 3.94$ in the second test, as seen in Table 2 above) mainly because the topics, contents, and difficulty level of all the texts are not biased in favor of a particular sex.

\section{The effect of text authenticity}

On the basis of the results observed in Table 4, the answer to the third research question is that reading authentic texts, generally, do not have any significant effect on the subjects' reading comprehension as compared to those of nonauthentic ones. Thus, the corresponding null hypothesis to this question verifies that reading authentic texts does not have much significant effect on the high school and pre-university students' reading comprehension. 
TABLE 4.

PAIRED T-TEST FOR STUDENTS' PERFORMANCE ON THE SECOND TEST WITH NON-AUTHENTIC PASSAGES AND THE FIRST TEST WITH AUTHENTIC TEXTS

\begin{tabular}{|c|c|c|c|c|}
\hline Subject & Test & Mean & SD & $\mathrm{t}_{O}$ \\
\hline \multirow[t]{2}{*}{ High school males } & Second non-authentic & 18.15 & 5.21 & \multirow[t]{2}{*}{5.27} \\
\hline & First authentic & 15.91 & 4.04 & \\
\hline \multirow[t]{2}{*}{ High school females } & Second non-authentic & 19.40 & 5.54 & \multirow{2}{*}{$1^{1.11}$} \\
\hline & First authentic & 19.01 & 5.26 & \\
\hline \multirow[t]{2}{*}{ Pre-university males } & Second non-authentic & 17.77 & 5.37 & \multirow[t]{2}{*}{1.20} \\
\hline & First authentic & 17.25 & 5.29 & \\
\hline \multirow[t]{2}{*}{ Pre-university females } & Second non-authentic & 19.01 & 5.93 & \multirow{2}{*}{$5^{2.22}$} \\
\hline & First authentic & 17.89 & 6.49 & \\
\hline
\end{tabular}

Since the genre, the type, the sources, and the difficulty level of the texts were similar in the two tests, the obtained results might be attributed to other interfering factors. In our view, one of the probable causes could be sought in the relationship between 'text structure (text organization) and content familiarity'. Two views that describe this relationship have come into vogue. The first states that the familiarity of the structure of a text is useful to readers who find the content to be unfamiliar (Roller, 1990, p. 81). In contrast, the second view states that the familiarity to the structure of the text is beneficial for the comprehension of both unfamiliar and familiar text contents (McKeown, Beck, Sinatra and Loxterman, 1992, P. 80). Lack of familiarity to the content and topic of authentic texts was partially compensated and controlled in the study by giving the students texts which were near in content (content schemata), difficulty level, and with approximately similar topics to the ones in their textbooks. This is because, according to the content schema (background knowledge of the content area of the text) as how to understand a text, one should have knowledge of the content words (lexical items) and how information is presented in various texts. However, they had less familiarity with the structure of such texts because of the oddity of such texts in their educational setting. It can be argued that the results of this study are pertained to what was hypothesized in the second view above.

The rationale for this prospect is that the subjects might have failed to benefit from the facilitative role of text structure, formal schema, to comprehend their contents. This issue can be in some way supported in the light of the comparisons between the subjects' performance in the first and second tests with authentic passages whose results are put in. The subjects' better performance, but not significantly enough, might be related to their greater acquaintance with the structure of such texts in the second tests. These tests contained authentic passages which were near in text difficulty and content to the previous ones. This point can be partially sustained taking into account the fact that no treatment was used in the current study. It is worthwhile to note that an intervention containing authentic texts could have possibly made the subjects more familiar with the organization of such texts.

\section{Conclusion and Pedagogical Implications}

Due to the tendency of testing task in affecting the test takers' developing mental model as well as their responses to subsequent testing tasks, it seems that a more valid test of reading comprehension ability would be the one which: a) taps the depth of processing required in the task of reading comprehension, b) regards the interaction of test method and mental model construction and c) lays stress on a multiple strategic measure of reading comprehension which can entail a 'storehouse' (Brown, 2004, p. 188) of macro- and micro-structures assessment in a text.

It is of outmost importance for researchers to identify the exact nature of different test formats and make research findings accessible to testing practice. For teachers, the multiple measure of testing reading comprehension in the present study can facilitate diagnosis of comprehension at different learning level. The same prescription would be made for classroom instruction, where the teacher provides practice on reading comprehension tests by written and oral reading comprehension tests.

In addition to implications that are directly related to the focus of this research, a few words must be said in favor of the use of qualitative methods for research in reading assessment. As was seen in this study, responses to different test items were based on a number of knowledge sources including information in the testing task itself. Consequently, because much research on the reading process is based upon the results of reading comprehension tests, invalid inferences might be made about comprehension processes if the processing involved in performing those tasks is not analyzed. Further research of this sort should be done in conjunction with more controlled empirical method so that reliable as well as valid information on the process of mental model construction and its assessment can be attained. 


\section{REFERENCES}

[1] Andre, T. (1979). Does Answering Higher-level Questions While Reading Facilitate Productive Learning? Review of Educational Research. 49(2), 280-318.

[2] Bachman, L. F. \& Palmer, A. S. (1996). Language Testing in Practice. Oxford: Oxford University Press.

[3] Bacon, S. M. (1992). The Relationship between Gender, Comprehension, Processing Strategies, and Cognitive and Affective Response in Foreign Language Listening. The Modern Language Journal. 76(2), 160-178.

[4] Beatie, B., Martin, L. \& Oberst, S. (1984). Reading in First-year College Textbook: A Syllabus for Textbook Authors, Publishers, Reviewers, and Instructors. The Modern Language Journal. 68(2), 203-211.

[5] Bem, L. B. (1983). Gender Schema Theory and Its Implications for Child Development: Raising Gender-schematic Children in a Gender-schematic Society. Signs. 8(4), 598-616.

[6] Bigler, R. S. \& Liben, L. S. (1990). The Role of Attitudes and Interventions in Gender-schematic Processing. Child Development. 61(9), 1440-1452.

[7] Brantmeier, C. (2003). Does Gender Make a Difference? Passage Content and Comprehension in Second Language Reading. Reading in a Foreign Language. 15(1), 1-14. http:// nflrc. hawaii. edu /rfl

[8] Brantmeier, C. (2004). Gender, Violence-oriented Passage Content and Second Language Reading Comprehension. The Reading Matrix. 4(1), 1-19. http://www.reading.org./pub./journals

[9] Brown, H. D. (2001). Teaching by Principles: An Interaction Approach to Language Pedagogy. San Francisco: Addison Wesley Longman, Inc.

[10] Brown, H. D. (2004). Language Assessment: Principles and Classroom Practice. San Francisco: Person Education, Inc.

[11] Bügel, K. \& Buunk, B.P. (1996). Sex Differences in Foreign Language Text Comprehension: The Role of Interests and Prior Knowledge. The Modern Language Journal. 80(1), 15-31.

[12] Bull, S. G. (1973). The Role of Questions in Maintaining Attention to Textual Material. Review of Educational Research. 43(1), 83-87.

[13] Cha, K. A. \& Swaffar, J. (1998). The Case for a Procedural Model as a Multiple Measure of Reading Comprehension. System. 26(2), 205-222.

[14] Chastain, K. (1988). Developing Second Language Skills: Theory and Practice. New York: Harcourt Brace Jovanish, Inc.

[15] Chen, H. S. (1993). Effects of Previewing and Providing Background Knowledge on Taiwanese College Students' Comprehension of American Short Stories. Unpublished doctorial dissertation, University of Minnesota, Minnesota: USA.

[16] Dunlap, J. A. (2006. The Effects of Self-questioning on Comprehension of Expository Text and Development of Content Writing with Second Grade Students. Unpublished MA Thesis, Wichita State University, Kansas.

[17] Ecroyd, C. A. (1991). Motivating Students through Reading Aloud. The English Journal. 80(1), 76-78.

[18] Ellis, A., Wulfeck, W. H. \& Montague, W. E. (1980). The Effect of Adjunct and Test Question Similarity on Study Behavior and Learning in a Training Course. American Educational Research Journal. 17(3), 449-457.

[19] Fairbairn, J. \& Fairbairn, S. A. (2001). Reading at University: A Guide for Students. Philadelphia: Open University Press.

[20] Farhady, H., Jafarpoor, A. \& Birjandi, P. (1996). Testing Language Skills: From Theory to Practice. Tehran: SAMT publication.

[21] Gatsakos, M. A. (2004). Reading Aloud and Its Effect on the Comprehension of Second-Grade Students. Unpublished doctorial dissertation, Northern Illinois University, Illinois.

[22] Gernsbacher, M. A. (1990). Language Comprehension as Structure Building. Hove: Lawrence Erlbaum.

[23] Gordon, \& D. Hanauer, C. M. (1995). The Interaction between Task and Meaning Construction in EFL Reading Comprehension Tests. TESOL Quarterly. 29(2), 299-324.

[24] Griswold, W. (1987). The Fabrication of Meaning: Literary Interpretation in the United States, Great Britain, and the West Indies. The American Journal of Sociology. 92(8), 1077-1117.

[25] Hamaker, C. (1986). The Effects of Adjunct Questions on Prose Learning. Review of Educational Research. 56(2), $212-242$.

[26] Harmer, J. (2001). The Practice of English Language Teaching. London: Pearson Education Limited.

[27] Kavale, K. \& Schreiner, R. (1979). The Reading Processes of above Average and Average Readers: A Comparison of the Use of Reasoning Strategies in Responding to Standardized Comprehension Measures. Reading Research Quarterly. 15(1), 102128.

[28] Kohn, E. (1994). Question-answer Relationship: An Effective Learner Strategy. Paper presented at the WATESOL Convention, Washington.

[29] Kools, M., Van de Weil, M. W. J., Ruiter, R. A. C., Crüts, A. \& Kok, G. (2006). The Effect of Graphic Organizers on Subjective and Objective Comprehension of a Health Education Text. Health Education \& Behavior. 33(4), 760-772.

[30] Langer, J. L. (1984). Examining Background Knowledge and Text Comprehension. Reading Research Quarterly. 19(3), 468481.

[31] McKeown, M. G., Beck, I. L., Sinatra, G. M. \& Loxterman, J. A. (1992). The Contribution of Prior Knowledge and Coherent Text to Comprehension. Reading Research Quarterly. 27(1), 79-93.

[32] Martin, C. L. \& Halverson, C. F. (1981). A Schematic Processing Model of Sex Typing and Stereotyping in Children. Child Development. 52(10), 1119-1134.

[33] Natkin, G. \& Stahler, E. (1969). The Effects on Adjunct Questions on Short and Long-Term Recall of Prose Materials. American Educational Research Journal. 6(3), 425-432.

[34] Nuttall, C. (1996). Teaching Reading Skills in a Foreign Language. Oxford: Macmillan Heinemann.

[35] Nyikos, M. (1990). Sex-related Differences in Adult Language Learning: Socialization and Memory Factors. The Modern Language Journal. 74(2), 273-284.

[36] Oded, B. \& Walters, J. (2001). Deep Processing for Better EFL Reading Comprehension. System. 29(3), 357-370.

[37] Pae, T. I. (2004). Gender Effect on Reading Comprehension with Korean EFL Learners. System. 32(2), $265-281$.

[38] Phakiti, A. (2003). A Closer Look at Gender and Strategy Use in L2 Reading. Language Learning. 53(4), 649-702. 
[39] Rickards, P. J. (1979). Adjunct Post Questions in Text: A Critical Review of Methods and Processes. Review of Educational Research. 49(2), 181-196.

[40] Roller, C. M. (1990). The Interaction between Knowledge and Structure Variables in the Processing of Expository Text. Reading Research Quarterly. 21(1), 79-89.

[41] Rothkopf, E. Z. (1970). The Concept of Mathemagenic Activities. Review of Educational Research. 1(2), 325-336.

[42] Salasoo, A. (1986). Cognitive Processing in Oral and Silent Reading Comprehension. Reading Research Quarterly. 21(1), 5969.

[43] Scott, K. P. (1986). Effects of Sex-fair Reading Materials on Pupils' Attitudes, Comprehension, and Interest. American Educational Research Journal. 23(1), 105-116.

[44] Silberstein, S. (1994). Techniques and Resources in Teaching Reading. Oxford: Oxford University Press.

[45] Snyders, S. M. (2005). The Effects of Collaborative Small Group Discussion on Comprehension, Written Expression, and Motivation Regarding Social Studies Content for Middle School Students. Unpublished doctorial dissertation, Purdue University, Indiana.

[46] Thompson, D. C. (1987). The Effects of Adjunct Questions on Learning from Text Inconsistent with Prior Knowledge. Unpublished doctorial dissertation, North Carolina State University, North Carolina.

[47] Winne, P. H., Graham, L. \& Prock, L. (1993). A Model of Poor Readers' Text Inferencing: Effects of Explanatory Feedback. Reading Research Quarterly. 28(1), 52-66.

[48] Wong, B. L. (1994). Instructional Parameters Promoting Transfer of Learned Strategies in Students with Learning Disabilities. Learning Disability Quarterly. 17(1), 110-120. 